pleasure, happy to extol virtues, condemn follies, and assure us which side he is on vis-à-vis the angels. There have been some splendid environmental battles in Florida, with some ghastly defeats and occasional victories; but these are tabulated in scant detail for those of us who wish to learn and profit from them. The chapter headings look well: An Ecosystem Enters Politics, The Great Barge Boondoggle, Repairs For the System, but there are too many retreats from the main subject for these to live up to their expectation. Alas!

Wilderness Areas of North America is, as they say these days (again and again), just that. There are a dozen well-written pages of introduction, discussing the value of wildernesses, and then 375 pages of concise description of over 500 wild areas in the whole of North America from top to toe. As there are also maps, lots of photographs, lesser indexes (there is a big one at the back), and plenty of white space, the average descriptive length for each place is much less than a page. Therefore it reads like the packaged literature handed out to, say, national park visitors. The book's blurb says it "serves as a guide to preliminary planning of wilderness trips in Canada, the USA, Mexico, Guatemala, Costa Rica, and Panama". It does just that.

ANTHONY SMITH

\title{
Breeding Endangered Species in Captivity, edited by R. D. Martin. Academic Press, £12.80.
}

This is a collection of the 37 papers given at a conference on the breeding of endangered animal species in Jersey in 1972, promoted by the Fauna Preservation Society and the Jersey Wildlife Preservation Trust. Some papers have been added to and brought up to date for publication. In his introduction the editor places special emphasis on the part that captive breeding should play in the overall conservation programme for a species, and this theme is evident throughout.

A few contributions deal specifically with the present status of a species in captivity, such as the Przewalski horse and the European bison, but the majority deal with the author's personal experiences, either with a family or a single species. Together they cover a wide variety of orders. On the whole, the most useful contributions tend to be those which consider the general approach to breeding a certain family or order such as those on "small mammals", marmosets, lemurs and wildfowl. In some cases (such as the paper on cheetahs) a summary of other peoples' experience is also given.

Some are essentially "recipes" of the type found in the Zoo Yearbooks, and often very frustrating to the reader who wants to use the information practically. For example, trade names (peculiar to one country) are given instead of chemical names, the contents of a "multivitamin preparation" are not given and the dose is expressed in "drops" (p. 323). Readers are recommended to give $3 \mathrm{ml}$. of a vaccine (p. 343), but the name is not given and the reader does not know whether it is dead or living. These are points which the editor should be more strict about.

Some gems of insight and forethought in overcoming specific problems appear regularly in the book. One example is the use of the relatively common sandhill crane to evaluate in advance the problems which might be encountered in rearing and later releasing the rare whooping crane. Problems of reintroduction are dealt with exclusively in a number of papers on birds. A few of the stories have been told before (Indian rhino and Arabian oryx) but they continue to serve as an illustration of what can be done with knowledge and intelligence.

The book contains a considerable volume of factual information as well as being a guide to general principles and an indicator as to the next steps needed. As such, it will be of value to the stock manager who is intimately involved in the problem of breeding captive animals. But its high price will discourage many potential buyers.

D. M. JONES 